\title{
Analysis of Wind Turbine Generation System by Using MATLAB
}

Vishal Badole ${ }^{1}$, Pankaj Katre ${ }^{2}$, Sagar Jadhav ${ }^{3}$, Dipavali Lanjewar ${ }^{4}$, Payal Nitnaware ${ }^{5}$, Mrugank Nandankar ${ }^{6}$, Prof. Atul S. Nikhade ${ }^{7}$

Students, Electrical Engineering Department, K.D.K. College of Engineering, Nagpur, India ${ }^{1,2,3,4,5,6}$

Asst. Professor, Electrical Engineering Department, K.D.K. College of Engineering, Nagpur, India ${ }^{7}$

\begin{abstract}
Wind energy is available everywhere in abundance, tapping this energy and utilizing it optimally is the need of the day. Renewable energy sources, especially wind turbine generators, are considered as important generation alternatives in electric power systems due to their non-exhausted nature and benign environmental effects. In this paper present an Probabilistically evaluation of generating systems by collecting the historical wind speed data over one years for the wind farm location to determine the necessary parameters of the wind speed models for the particular site. The system reliability shows the availability and the power generation model. In this work the basic system reliability indices are calculated. This study shows the probabilistic analysis of wind power generation from wind turbine generators installed at geographic locations.
\end{abstract}

Keywords: Wind energy, reliability evaluation, WTG, probabilistic model.

\section{INTRODUCTION}

Wind is one of the fastest growing energy sources, and is regarded as an important alternative to traditional power generating sources. Wind turbine generators (WTG) are an ideal choice in many developing countries where there are urgent needs to supply basic electricity. The basic function of a power system is to supply the customer demands in both large and small within the economic limits in an acceptable reliability and quality. Many utilities throughout the world are considering using wind energy as a substitute for conventional generation because of its huge potential and minimal pollution.

In a wind turbine, the kinetic energy of the wind acting on the rotor blades is converted into torque or mechanical energy for rotating the shaft which is then transferred through the gear box to the generator and the generator produce electrical energy. The project reveals a reliability planning method for a generating system with a wind energy system with a wind energy conversion system (WECS).The electricity production by a WECS in a given area is depending on many factors. These factors include the wind speed conditions in the area and the characteristic of the wind turbine generator particularly the cut-in, rated and cut-out wind speed parameters. A wind turbine is not operational when the speed is below the cut-in speed and will be stopped for safety reasons if the wind speed is higher than the cut-out speed. In both the extreme cases, the power output is zero. Different types of wind turbine are commercially available on the market. Wind turbines range from less than $1 \mathrm{KW}$ to as large as $5 \mathrm{MW}$ or more. This method gives an idea of characteristic of WTG based on wind speed associated to a given area, but completely ignores the load profile. Having in view this issue, the project aims reliability evaluation method applied to have comparison between different WTG types included in WECS and to evaluate the reliability parameters.

\section{RELIABILITY EVALUATION OF ELECTRICITY GENERATING SYSTEM}

The basic generating unit parameter used in static capacity evaluation is the probability of finding the unit on forced outage at some distant time in the future in the generation system the total system generation is evaluated to find the system adequacy to meet the total system load demand. The system model in generation is shown in the figure 1 .

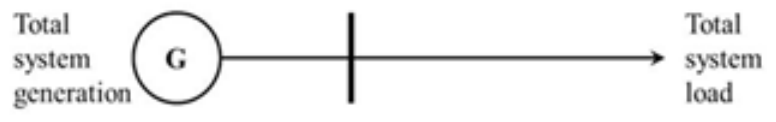

Fig.1 Generation system reliability model

\section{RELIABILITY INDICES}

Reliability has been and always is one of the major factors in the planning, design, operation, and maintenance of electric power system. Generation system reliability focuses on the reliability of generators in the whole electric power system where electric power is produced from the conversion process of primary energy (fuel) to electricity before transmission. The generation system is an important part of the electricity supply chain and it is crucial that enough electricity is generated at every moment to meet the demand. Generating units will occasionally fail to operate and the system operator has to 


\section{International Journal of Innovative Research in Electrical, Electronics, Instrumentation and Control Engineering}

\section{ISO 3297:2007 Certified}

Vol. 5, Issue 2, February 2017

make sure that enough reserve is available to be operated when this situation happens. Reliability of the generation system is divided into adequacy and security. System adequacy relates to the existence of sufficient generators within the system to satisfy the consumer load demand or system operational constraints. In this study, the reliability evaluations will be focused on the generation system adequacy and will not take into account system security. The quantification of reliability is an important aspect of generation system reliability assessment. The measurement used to quantify reliability of a generation system is given various reliability indices. These reliability indices are used to assess the reliability performance of a generation system against some predetermined minimum requirements or reliability standards, compare alternative designs, identify weak spots and determine ways for correction in the generation system and to be integrated with costs and performance considerations for decision making. These indices are better understood as estimates of system-wide generation adequacy and not as absolute measures of system reliability.

ENERGY INDEX OF RELIABILITY (EIR)

It is the Energy Index of Reliability and is given by,

$$
\text { EIR }=1-\frac{\text { EENS }}{\text { EnergyDemand }}
$$

\section{WIND TURBINE PARAMETERS}

1. POWER COEFFICIENT: With the help of wind blades the kinetic energy of wind is converted into mechanical energy which is used to drive the shaft of wind generator. The power coefficient $C_{p}$ converting efficiency is given as:

$$
C_{p}=\frac{P_{\text {me. Out }}}{P_{w}}=\frac{P_{\text {me.Out }}}{\left(\frac{1}{2}\right) \rho A V^{3}}
$$

Where, $\mathrm{P}_{\mathrm{me}}$ Out - Captured Mechanical, PowerP $\mathrm{w}^{-}$ Available Wind Power - Air Density, A - Blade Swiftness

2. POWER CONVERSION EFFICIENCY $(\eta)$ : The total power conversion efficiency from wind to electricity is given by,

$$
\eta=C_{p} \eta_{\text {gear }} \eta_{\text {gen }} \eta_{\text {ele }}
$$

Where, $\eta_{\text {gear }}$-Gearbox Efficiency; $\eta_{\text {gen }} \quad-$ Generation Efficiency; $\eta_{\text {ele }}-$ Electrical Efficiency.

3. CUT IN WIND SPEED: This is the minimum wind speed at which the turbine blades overcome friction and begin to rotate.

4. CUT OUT WIND SPEED: This is the speed at which the turbine blades are brought to rest to avoid damage from high winds. Not all turbines have a well-defined cutout speed.

5. RATED WIND SPEED: Wind turbines are most B commonly classified by their rated power at a certain wind $\mathrm{C}$. speed. The rated power is usually defined as the maximum power output and the rated wind speed is the wind speed at which the turbine reaches its rated power output.

\section{WIND TURBINE POWER GENERATION} EVALUATION: This is the data obtained from the turbine manufacturers installed at the wind site. This data contains the power output of the wind turbine generator at different wind speed and the rated wind speed for the rated power output, cut-in wind speed, cut-out wind speed of the wind turbine. The probabilistic evaluation of the generated power at different wind speeds through the year. This is calculated by combining distribution of discrete wind speeds. This can be calculated by estimated energy output by the discrete wind speed and total energy estimated through the year. The power generated can be calculated using the power formula given in equation

$$
\mathrm{Pm}=\mathrm{Cp}\left(\frac{1}{2} \rho A V^{3}\right) \ldots \ldots \ldots \text { watts. }
$$

Where, $\mathrm{Cp}$ is the capacity factor given by the turbine manufacturer

$\rho$ is air density at the wind site $\mathrm{kg} / \mathrm{m} 3$

$\mathrm{A}$ is area swept by the turbine in $\mathrm{m}^{2}$

$u$ is the wind speed in $\mathrm{m} / \mathrm{sec}$

\section{THREE STATE MODEL FOR WTG SYSTEM}

The output of a wind turbine generator (WTG) is a function of the wind speed. In this work the WTG is represented by a three-state model. State Up1, State Up2 and State Down are three states, which represent variable, constant and no outputs, respectively, in terms of wind speed variation. The WTG three-state model is shown in Figure. A wind farm usually consists of many units and therefore the specified wind velocity is assumed to be the same for all the units in the farm. The power output of a wind farm is the summation of the output of all the available units. The probability of turbine being in three different states is calculated according to the state representation and it is described by the relation as shown below. Probability of WTG in state UP1 is,

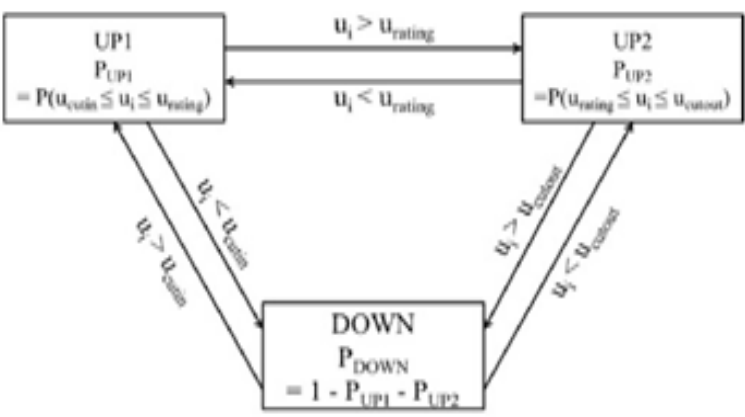

Fig. 2 Three state model for WTG system

A. $\quad$ PUP $1=\mathrm{P}$ (ucutin $\leq$ ui $\leq$ urating)

Probability of WTG in state UP2 is,

PUP2 $=$ P(urating $\leq$ ui $\leq$ ucutout)

Probability of WTG in state DOWN is 


\section{ISO 3297:2007 Certified}

Vol. 5, Issue 2, February 2017

\section{E. $\quad$ PDOWN = 1 - PUP1 - PUP2 Units}

Where, ui is the measured wind speed at the interval.

\section{CALCULATION OF PLANT FACTOR AND PLANT AVAILABILITY FACTOR}

Since wind speed is not constant and continuous, a wind farm's annual power production is never as much as the sum of the generator nameplate ratings multiplied by the total hours in a year. Plant factor is the theoretical maximum ratio of actual productivity in a year. Typical Plant factors [4] are 15- 50\%; values at the upper end of the range are achieved in favourable sites and are due to wind turbine design improvements.

The plant factor is calculated by the formula given by, \%PLANT FACTOR =

\section{ACTUAL POWER GENERATED IN SIMULATED TIME \\ RATED POWER GENERATED IN SIMULATED TIME $\times 100$}

The value of plant factor between $15 \%$ to $50 \%$ is better for wind power generation. When wind is continuous the plant factor will more the plant availability is the wind turbine generator which is available to generate electric power. This is obtained by following equation

PLANT AVAILABILITY FACTOR = PLANT AVAILABLEFOR GENERATION IN HOURS

TOTAL HOURS IN THE SIMULATED DATA $\times 100$

PLANT UNAVAILABILITY $=1-$ PLANT

CALCULATION FOR LOLE: The basic reliability index used in this work is loss of load expectation. It is the average number of hours for which the load expected to exceed the available generating capacity.

And it is given by equation,

LOLE $=\frac{1}{\mathrm{~N}} \sum$ PiTi ............. hours $/$ year

\section{WIND ROSE GRAPH}

A wind rose is a chart which gives a view of how wind speed and wind direction are distributed at a particular location over a specific period of time. It is a very useful representation because a large quantity of data can be summarized in a single plot. The first step to plot a wind rose with an electronic data sheet is to organize the wind data in a table according to their direction and speed classes. In other words the joint distribution of wind direction and speed must be calculated, as shown for example in the next figure. Each yellow cell contains the number of events observed over a specific time period for a specific combination of wind direction and speed. For example, wind blowing from North $(\mathrm{N})$ with a speed smaller than $1 \mathrm{~m} / \mathrm{s}$ has been observed 51 times, while wind blowing from North East (NE) with speed between $1 \mathrm{~m} / \mathrm{s}$ and $2 \mathrm{~m} / \mathrm{s}$ has been observed 159 times. If available, the user may also specify the average wind speed for each direction, as shown for example in the green cells. The total number of events and the corresponding percentages for each direction and wind speed class are automatically updated. The example file uses 16 directions and 6 wind speed classes, but their number and contents can be easily modified. Once the number of observations for each direction and wind speed class has been specified for each yellow cell, three charts are produced: the wind rose, the wind direction distribution and the wind speed distribution. If the average wind speed for each direction is also specified, then a fourth chart is produced representing the rose of the average wind. The joint distribution of wind direction and speed must be determined by the user. This task might require long times, particularly for large time series of data. In a wind rose the length of each arm is proportional to the number of events, or the frequency, at which wind was observed from that direction. For a specific direction, the different wind speed frequencies sum up to give the total length of the arm. The wind rose plotted with the Microsoft Excel or Open Office files does have such feature. If you need more professional wind roses and more complex analysis of your data, you might want to evaluate Wind Rose PRO.

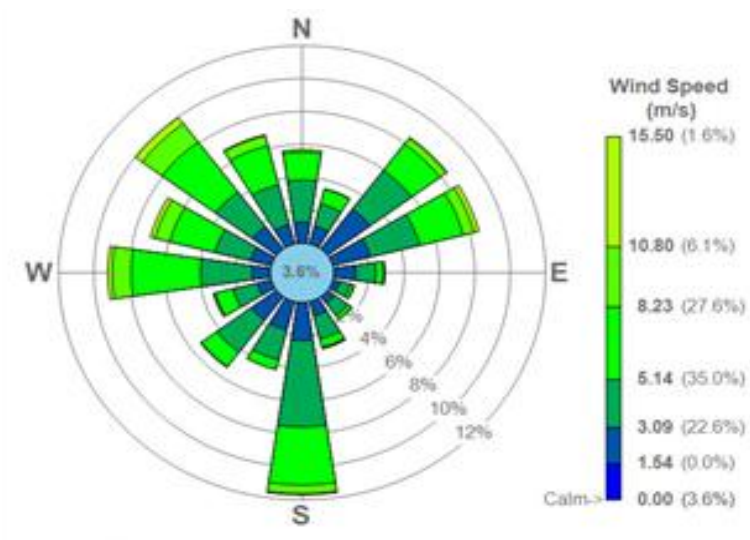

Fig.3 Wind rose diagram

\section{REFERENCES}

[1] R. Karki and R. Billinton, "Cost-effective wind energy utilization for reliable power supply," IEEE Trans. Energy Convers., vol. 19, no. 2, pp. 435-440, Jun. 2004. R. Karki and P. Hu, "Wind power simulation model for reliability evaluation," in Proc. IEEE Can. Conf. Electr. Comput. Eng., Saskatoon, May1-4, 2005, pp. 541-544.

[2] R. Billinton and S. Kumar, "A reliability test system for educational purposes - Basic data," IEEE Trans. Power Syst., vol. 4, no. 3, pp. 1238-1244, Aug. 1989.

[3] S. M. Pandit and S. M. Wu, Time Series and System Analysis With Application. New York: Wiley, 1983.

[4] I. Abouzahr and R. Ramakumar, "An approach to assess the performance of utility-interactive wind electric conversion systems, "IEEE Trans. Energy Convers., vol. 6, no. 4, pp. 627-638, Dec. 1991

[5] R. Karki and P. Hu, "Wind power simulation model for reliability evaluation," in Proc. IEEE Can. Conf. Electr. Comput. Eng., Saskatoon, May 1-4, 2005, pp. 541-544

[6] R. Billinton and G. Bai, "Generating capacity adequacy associated with wind energy," IEEE Trans. Energy Convers., vol. 19, no. 3, pp. 641-646, Sep. 2004

7] R. Billinton, H. Chen, and R. Ghajar, "Time-series models for reliability evaluation of power systems including wind energy," Microelectron. Reliab., vol. 36, no. 9, pp. 1253-1261, 1996. 